\title{
Étude de la contamination microbienne et de la dégradabilité ruminale in sacco des matières azotées de 2 variétés de ray-grass italien marquées au moyen de $15 \mathrm{~N}$ et récoltées à 2 stades végétatifs
}

\author{
M Kamoun 1, A Théwis 1, L Couvreur 2, E François 2 \\ 1 Faculté des Sciences agronomiques de Gembloux, UER de Zootechnie, \\ passage des déportés, 2, B 5030 Gembloux; \\ ${ }^{2}$ Centre de Recherches agronomiques, avenue de la Faculté-d'Agronomie, 22, \\ B 5030 Gembloux, Belgique
}

\begin{abstract}
Summary - Microbial contamination and in sacco ruminal degradability of nitrogen from 2 varieties of ${ }^{15} \mathrm{~N}$ labelled Italian ray-grass at 2 stages of maturity. Ruminal degradation (RD) of crude protein in 2 varieties of ${ }^{15} \mathrm{~N}$-labelled Italian ray-grass cut at 2 stages of maturity was studied in sheep by the in sacco method. Data showed a very high microbial contamination of the residues in the bags resulting in $\mathrm{RD}$ errors ranging from $15-25 \%$.
\end{abstract}

Pour les fourrages verts frais, les valeurs de dégradabilité in sacco des protéines sont généralement nettement inférieures aux données obtenues in vivo. L'objectif de ce travail est de mesurer, au moyen de fourrages marqués au ${ }^{15} \mathrm{~N}$, l'importance de la contamination microbienne et son incidence sur les valeurs de dégradabilité théorique (DT) des matières azotées totales (MAT) de 2 variétés de ray-grass italien (Lolium multiflorum) récoltées à 2 stades végétatifs.

Matériel et méthodes - Les matières azotées de 2 variétés de ray-grass italien, une diploïde (D) et une tétraploïde (T), ont été marquées par pulvérisation de ${ }^{15} \mathrm{NH}_{4}{ }^{15} \mathrm{NO}_{3}$ (enrichissement : $5 \%$ ) et de $\mathrm{NH}_{4} \mathrm{NO}_{3}(50 / 50 \mathrm{~W} /$ W) sur la culture à raison de $80 \mathrm{U}$ de $\mathrm{N} / \mathrm{ha}$ appliqués à 30 ou 48 j avant la récolte. Celle-ci a eu lieu le 19/05/1988 (St1) et le 06/06/1988 (St2). L'herbe a été immédiatement congelée à $-20^{\circ} \mathrm{C}$, lyophylisée et finalement moulue au broyeur à marteaux (tamis de $1 \mathrm{~mm}$ ). Les valeurs de la teneur en MAT et de la digestibilité de la MO étaient de : $13,8 \%$ et 0,80 pour DSt 1 ; $8,6 \%$ et 0,74 pour DSt2; $15,3 \%$ et 0,82 pour TSt $1 ; 9,5 \%$ et 0,77 pour TSt2. En vue de suivre la cinétique de dégradation des MAT, des sa- chets de nylon $(20 \times 10 \mathrm{~cm}, 42,5 \mu \mathrm{m}$ de porosité; 2 sachets/point de cinétique) contenant $5 \mathrm{~g}$ de matière sèche, ont été incubés dans le rumen de 3 béliers adultes pendant $3,6,12,24$ et $48 \mathrm{~h}$. Les animaux recevaient en 2 repas/j une ration constituée de $1,2 \mathrm{~kg}$ de foin de prairie et de $0,6 \mathrm{~kg}$ de concentré. Dans les aliments et les résidus des sachets de nylon, on a dosé l'azote total et l'excès isotopique en ${ }^{15} \mathrm{~N}$. Celuici a été mesuré au moyen d'un spectromètre de masse à double système d'introduction (VG, Syra12) selon la méthode de KjeldahlRittenberg. Pour chaque point de cinétique, on a calculé la part d'azote d'origine microbienne dans l'azote total résiduel des sachets à partir du rapport des excès isotopiques des résidus et du fourrage ainsi que le taux de disparition de l'azote. DT $(k=0,06)$ a été déterminée au moyen du modèle de Ørskov et McDonald (1979).

Résultats et discussion - La proportion d'azote d'origine microbienne dans l'azote total résiduel in sacco varie entre $40 \%$ après $3 \mathrm{~h}$ d'incubation et $76 \%$ après $48 \mathrm{~h}$. On a constaté une grande variabilité entre animaux et une contamination plus importante pour la variété tétraploïde après 3,6 et $12 \mathrm{~h}$ d'incubation. Ces valeurs sont du même ordre de grandeur que celles obte- 
nues par Ould Bah (1989) lors de la perfusion de ${ }^{15} \mathrm{~N}$ dans le rumen, mais sont nettement supérieures à celles obtenues par Varvikko et Lindberg (1985) travaillant avec un ray-grass marqué. Les faibles teneurs en MAT des fourrages étudiés et leur lyophilisation plutôt que le séchage à l'étuve pourraient expliquer cette différence. Par ailleurs, la technique utilisée prend en considération tous les microorganismes susceptibles de se fixer aux particules; elle donne de ce fait des taux de contamination supérieurs à ceux obtenus avec le DAPA, dont la concentration varie selon le type de bactéries considérées (Teller et Vanbelle, 1990). II est étonnant, dans cette expérience, de ne pas observer de différence de contamination microbienne entre fourrages ayant des teneurs en MAT très différentes. Cela est en contradiction avec les observations de Teller et Vanbelle (1990), Ould Bah (1989) et Varvikko et Lindberg (1985).

Du fait de l'importante contamination microbienne, les DT corrigées et non corrigées des MAT des fourrages étudiés ont été très différentes, l'erreur se situant entre 15 et $25 \%$ (tableau I). On n'a toutefois pas obtenu de différence ni en fonction du stade végétatif contrairement à Van Vuuren et al (1991), ni entre variétés.

En conclusion, pour les fourrages verts frais, la contamination microbienne des résidus dans les sachets de nylon devrait être prise en compte de manière plus spécifique qu'actuellement lors de l'évaluation de la DT. Toutefois, une étude plus complète, notamment avec des fourrages verts plus riches en MAT, s'impose.

Ørskov ER, McDonald I (1979) J Agric Sci (Camb) 92, 449-503

Ould Bah M (1989) Adaptation de la technique in sacco à l'étude de la dégradation dans le rumen de l'azote des fourrages et application à l'étude des fourrages verts et conservés. Thèse de doctorat Montpellier, $186 p$

Teller E, Vanbelle M (1990) Reprod Nutr Dév (suppl 2) 155s-156s

Van Vuuren AM, Tamminga $S$, Ketelaar RS (1991) J Agric Sci (Camb) 116, 429-436

Varvikko T, Lindberg JE (1985) Br J Nutr 54, 473-481

Tableau I. Dégradabilités ruminales théoriques in sacco (\%) des matières azotées totales de 2 variétés de ray-grass italiens récoltées à 2 stades végétatifs avec $\left(D T_{c}\right)$ ou sans ( $\left.D T_{n c}\right)$ correction pour la colonisation microbienne des résidus $(\bar{x} \pm \sigma)$.

\begin{tabular}{lccc}
\hline Fourrages & $D T_{n c}$ & $D T_{c}$ & Erreur' \\
\hline D St 1 & $74 \pm 2,4$ & $85 \pm 3,5$ & -15 \\
D St 2 & $73 \pm 1,3$ & $85 \pm 3,0$ & -18 \\
T St 1 & $72 \pm 1,6$ & $86 \pm 2,0$ & -19 \\
T St 2 & $70 \pm 2,5$ & $88 \pm 2,7$ & -25 \\
\hline
\end{tabular}

${ }^{1}$ Erreur $(\%)=\left(1-\frac{\text { DTc }}{\text { DTnc }}\right) \times 100$. 